\title{
CONTINUOUS PERFUSION OF DONOR HEARTS IN THE BEATING STATE EXTENDS PRESERVATION TIME AND IMPROVES RECOVERY OF FUNCTION
}

Waleed H. Hassanein, MD

Lambros Zellos, MD

Tracey A. Tyrrell, BA

Nancy A. Healey, BS

Michael D. Crittenden, MD

Vladimir Birjiniuk, MD

Shukri F. Khuri, MD
Objectives: Improving methods of donor heart preservation may permit prolonged storage and remote procurement of cardiac allografts. We hypothesized that continuous, sanguineous perfusion of the donor heart in the beating, working state may prolong myocardial preservation. Methods: We developed a portable perfusion apparatus for use in donor heart preservation. Contractile, metabolic, and vasomotor functions were monitored simultaneously in an isolated swine heart. The metabolic state was monitored by myocardial tissue $\mathrm{pH}$. Vasomotor function was assessed in isolated coronary ring chambers. Hearts were randomized into 3 groups: group $I(n=5)$, cardioplegic arrest, 12-hour storage at $4^{\circ} \mathrm{C}$ with modified Belzer solution, and 2-hour sanguineous reperfusion in the working state; group II $(n=6)$, 12-hour continuous perfusion in the beating working state, 30 minutes of arrest (to simulate re-implantation time), and 2 hours of reperfusion, as above; group III $(\mathbf{n}=7)$, coronary ring control hearts. Results: At 2 hours of reperfusion, left ventricular developed pressure in group II was higher than in group I (mean \pm standard deviation: $90 \pm 6 \mathrm{~mm} \mathrm{Hg}, 53 \pm 15 \mathrm{~mm} \mathrm{Hg}, P=.005$ ). Significantly less myocardial edema was observed in group II than in group I (73\% $\pm 4 \%, 80 \% \pm 1 \%$ water content, $P=.01)$. Significantly less myocardial acidosis was noted in group II than in group I during preservation $(\mathrm{pH} 7.3 \pm 0.01,6.1 \pm 0.03, P<.001)$ and reperfusion $(\mathrm{pH} 7.3 \pm$ $0.008,6.8 \pm 0.05, P<.001)$. Coronary endothelial vasomotor function was better preserved in group II than in group I as evidenced by doseresponse relaxation of coronary rings to $10^{-8} \mathrm{~mol} / \mathrm{L}$ bradykinin $(37 \%$, $55 \% \Delta$ baseline, $P=.01)$. Conclusion: This new method extends the current preservation limit and avoids time-dependent ischemic injury, thereby allowing for distant procurement of donor organs. (J Thorac Cardiovasc Surg 1998;116:821-30) $\int_{\text {qua }}$ espite numerous investigations aimed at improving the quality of donor hearts and prolonging the preservation time, few changes have been made in the clinical

From the Department of Surgery, Brockton/West Roxbury Veterans Administration Medical Center, Brigham and Women's Hospital, Harvard Medical School, Boston, Mass.

This work was supported by a Veterans Administration Medical Research Merit Review Grant and Richard Warren Surgical Research and Educational Fund, Westwood, Mass.

Read at the Seventy-eighth Annual Meeting of The American Association for Thoracic Surgery, Boston, Mass, May 3-6, 1998.

Received for publication April 6, 1998; revisions requested May 13, 1998; revisions received June 12, 1998; accepted for publication July 17, 1998.

Address for reprints: Shukri F. Khuri, MD, Chief, Department of Surgery, West Roxbury VA Medical Center, 1400 VFW Parkway, MA 02132.

$12 / 6 / 93304$ practice of donor heart preservation during the past 20 years. ${ }^{1-3}$ Current preservation protocols use hypothermic arrest and simple storage, using a variety of crystalloidbased cardioplegic and preservation solutions. These techniques limit organ procurement and safe storage time to 4 to 6 hours. In addition, they invariably subject donor hearts to periods of ischemia and thus may result in time-dependent ischemia-reperfusion injuries. The use of blood perfusates has been suggested as a more suitable method for clinical donor heart preservation. ${ }^{4-8}$ We hypothesized that continuous, sanguineous perfusion of the donor heart in the beating, working state would result in a homogeneous distribution of substrate and might prevent time-dependent ischemia-reperfusion injury, thus prolonging the preservation period. This study uses an isolated swine heart model to compare continuous sanguineous perfusion of the donor heart in the beating, working state to standard hypothermic storage in the arrested state. 


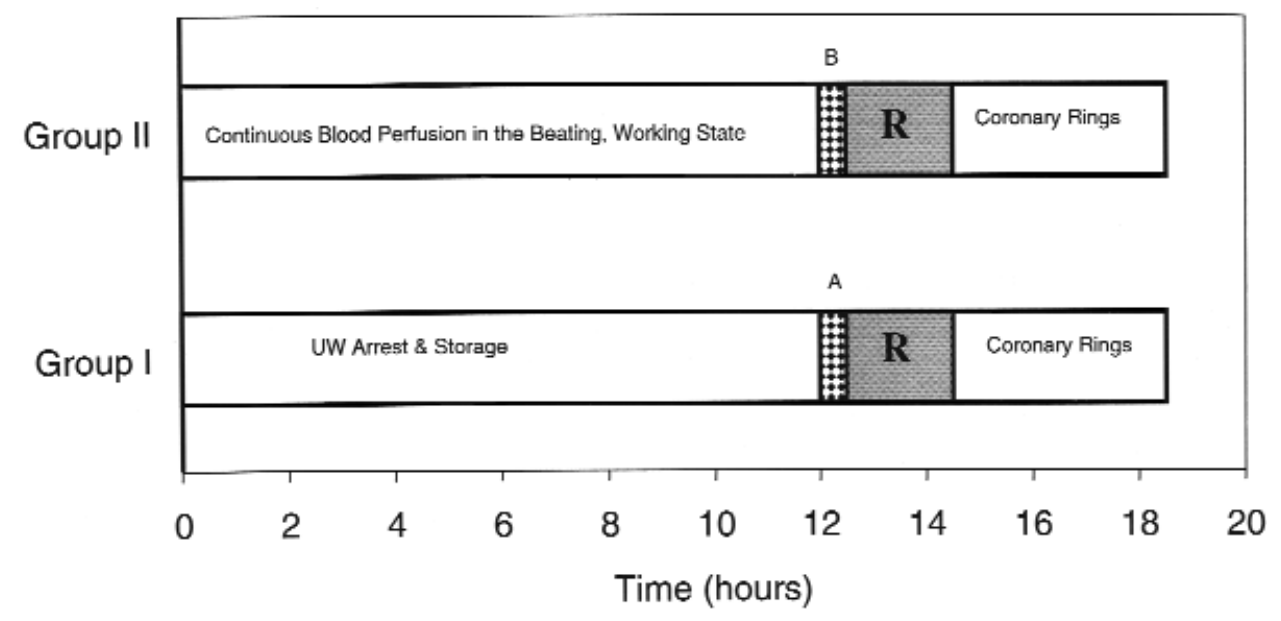

Fig 1. Timeline of the study protocol. The 30-minute period $(A)$ in group I (UW) represents the period for gradual rewarming and instrumentation of the heart in preparation for reperfusion. The 30-minute period $(B)$ in group II (blood) represents blood cardioplegic arrest. $R$, Two-hour reperfusion period.

\section{Methods}

The protocol was approved by our institutional animal care committee in accordance with the 1996 "Guide for the Care and Use of Laboratory Animals" prepared by the Institute of Laboratory Animal Resources of the National Research Council and published by the National Academy Press.

Animal preparation. Twenty-nine male Yorkshire pigs (90-100 kg) were premedicated with intramuscular ketamine $(20 \mathrm{mg} / \mathrm{kg}$ ) and intramuscular xylazine $(2 \mathrm{mg} / \mathrm{kg}$ ), intubated, and their lungs mechanically ventilated with $100 \%$ oxygen. Anesthesia was maintained with $1 \%$ to $2 \%$ isoflurane. The right femoral artery and vein were isolated and cannulated for hemodynamic monitoring and support. A median sternotomy was performed and the pericardium was opened. After isolation of the great vessels, heparin was infused at a rate of 200 $\mathrm{U} / \mathrm{kg}$ to achieve an activated clotting time of 400 seconds or more. A Khuri tissue $\mathrm{pH}$ electrode (Vascular Technology, Inc, Lowell, Mass) was inserted into the anterior ventricular wall for on-line measurement of myocardial $\mathrm{pH}$. Hearts were randomized into 1 of the 3 groups (Fig 1).

\section{Experimental groups.}

Group I: Arrest with and simple immersion in $4^{\circ} \mathrm{C}$ University of Wisconsin solution ( $U W$ solution, $n=5$ ). After the instruments were inserted as described herein, the aorta was crossclamped. Hearts were arrested by antegrade infusion of $1000 \mathrm{~mL}$ of UW solution (prepared according to DuPont guidelines [EI du Pont de Nemours and Company, Wilmington, Del] by adding $40 \mathrm{U}$ of regular insulin, $16 \mathrm{mg}$ of dexamethasone, and $200,000 \mathrm{U}$ of penicillin G) into the aortic root at a perfusion pressure of 50 to $60 \mathrm{~mm} \mathrm{Hg}$ and a temperature of $4^{\circ} \mathrm{C}$. Cardioplegic solution was vented through venotomies in the inferior vena cava and the left superior pulmonary vein. Hearts were excised and immediately immersed in a plastic bag filled with $1500 \mathrm{~mL}$ of UW solution. A second Khuri tissue $\mathrm{pH}$ electrode was placed in the posterior wall of the left ventricle. The heart was stored on ice for 12 hours. At the end of the preservation period, hearts were flushed with $500 \mathrm{~mL}$ of normal saline solution at room temperature and then sanguineously reperfused for 2 hours, as described in the Reperfusion protocol section.

Group II: Normothermic blood-perfused hearts in the beating, working state (blood group, $n=6$ ). After instrumentation as described herein, the right atrium and the inferior vena cava were cannulated with a $28 \mathrm{~F} / 36 \mathrm{~F} 2$-staged venous cannula (DLP, Inc, Grand Rapids, Mich), which was clamped and connected to the perfusion circuit (Fig 2). At the time of aortic crossclamping, the 2-staged cannula was unclamped to exsanguinate the animal into the perfusion circuit. Blood in the perfusion circuit was oxygenated with $95 \%$ oxygen $/ 5 \%$ carbon dioxide at a rate of $2 \mathrm{~L} / \mathrm{min}$ and warmed to $37^{\circ} \mathrm{C}$ with a hollow-fiber membrane oxygenator (Minimax, Medtronic Inc, Anaheim, Calif). A leukocyte-depleting filter (Pall Filters Biomedical Products Corp, East Hills, NY) was used in the perfusion circuit during the preservation protocol. Hearts were immediately dissected and perfused through the aortic root (nonworking model) with a $28 \mathrm{~F}$ arterial cannula that was connected to one arterial end of the perfusion circuit. The pulmonary artery was cannulated with a $28 \mathrm{~F}$ arterial cannula and connected to the venous reservoir of the perfusion circuit for collection of the coronary effluent. Coronary flow and aortic flow were measured by placing $6 \mathrm{~N}$ flow probes (Transonic Systems, Ithaca, NY) on the pulmonary artery and the aortic cannula, respectively. The pulmonary veins and the superior and inferior venae cavae were tied off. A Mikro-Tip pressure transducer (Millar Instruments, Inc, Houston, Tex) was placed into the left ventricle through the left superior pulmonary vein to measure intracavitary pressures. A second Khuri tissue $\mathrm{pH}$ electrode was placed in the posterior left ventricular wall. A $22 \mathrm{~F}$ arterial cannula, connected to the second arterial line of the perfusion circuit, was placed into the 


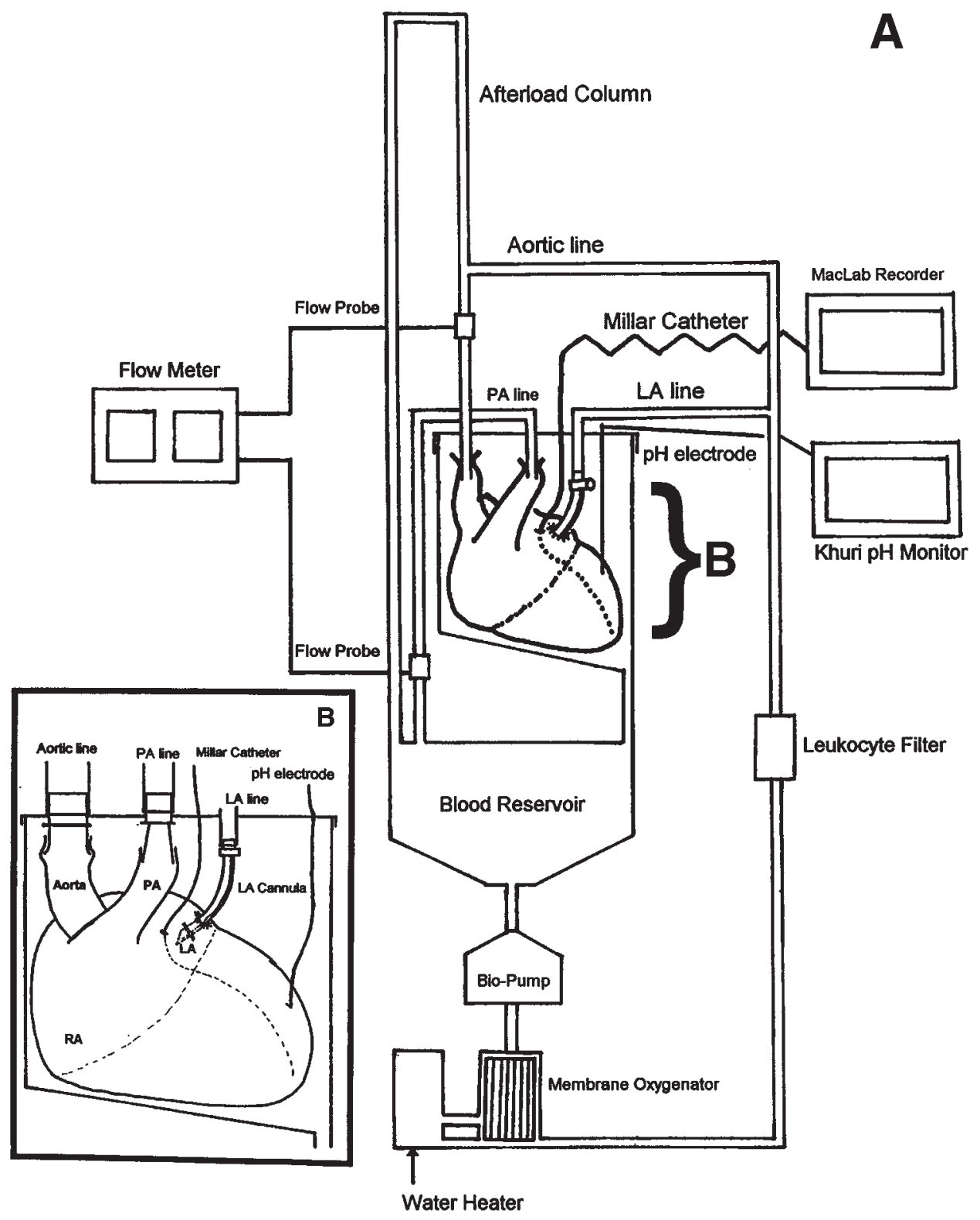

Fig 2. Schema of perfusion apparatus. Panel A shows the monitoring equipment and chamber for the heart. Panel $\mathbf{B}$ is a detailed enlargement of the heart chamber depicting the instrumentation. $L A$, Left atrium; $R A$, right atrium; $P A$, pulmonary artery.

left atrium via the right superior pulmonary vein and secured with a purse-string suture. This cannula was used as the perfusion line in the working heart model. The inflow to the aorta was gradually reduced and blood flow to the left atrium was increased to change the heart to a working state for the 12-hour preservation period. During this period the pump flow and afterload column height were adjusted to achieve coronary blood flow of 1 to $2 \mathrm{~mL} / \mathrm{g}$ wet heart weight per minute. At 6 hours of preservation, 1500 to $2000 \mathrm{~mL}$ of the circulating blood was drained off the perfusion circuit and replaced by a similar volume of fresh homologous blood. At the end of the preservation period, the hearts were arrested with standard 4:1 blood/cardioplegic solution (in a $500 \mathrm{~mL}$ mixture of $2.5 \%$ dextrose, $0.25 \% \mathrm{NaCl}, 25 \mathrm{mmol} / \mathrm{L} \mathrm{KCl}$, and $50 \mathrm{mmol} / \mathrm{L} \mathrm{NaHCO}_{3}$ added to the heparinized blood just before use) at a perfusion pressure of 50 to $60 \mathrm{~mm} \mathrm{Hg}$ and a temperature of $20^{\circ} \mathrm{C}$ to $22^{\circ} \mathrm{C}$ for 30 minutes to simulate reimplantation time. At the end of 30 minutes of arrest, all hearts were sanguineously reperfused with fresh homologous blood from another swine (see Reperfusion protocol). 


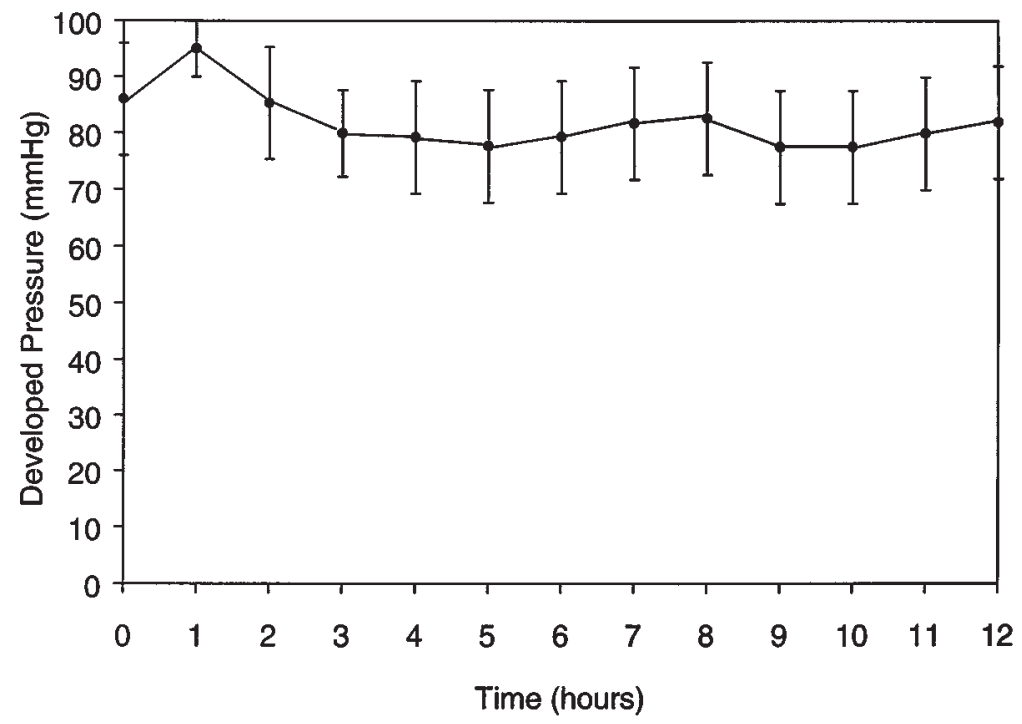

Fig 3. Mean developed pressure for group II (blood, $n=6$ ) hearts during the 12-hour preservation period. Data are expressed as mean \pm standard error of the mean.

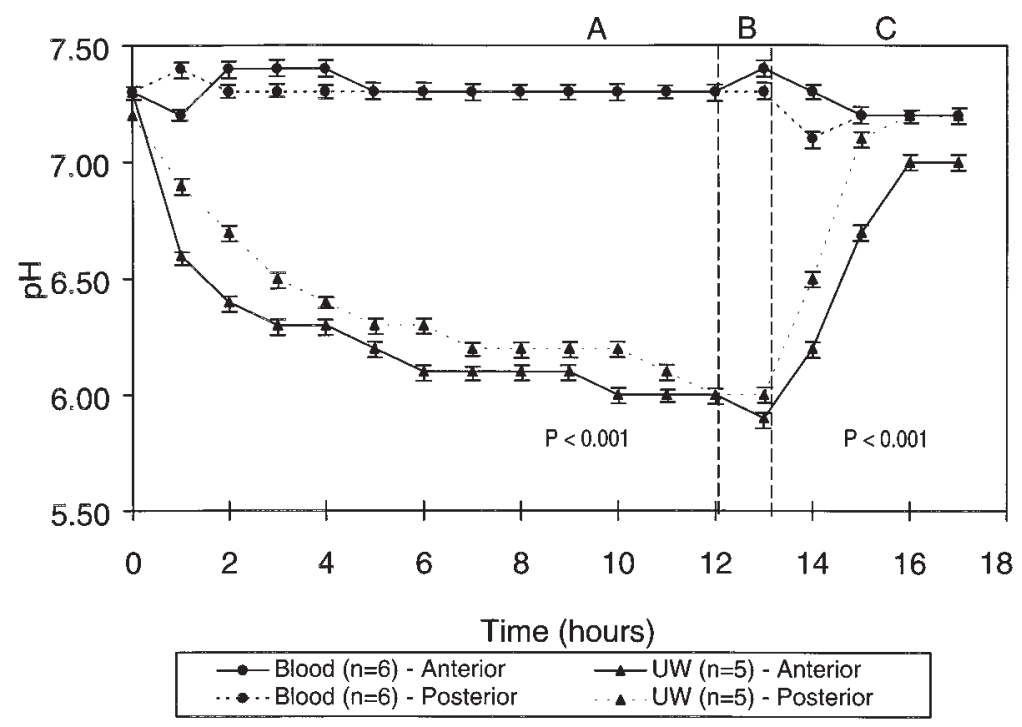

Fig 4. Myocardial tissue $\mathrm{pH}$ (normalized for $37^{\circ} \mathrm{C}$ ) for group $\mathrm{I}(\mathrm{UW}, \mathrm{n}=5$ ) and group II (blood, $\mathrm{n}=6$ ) in the anterior and posterior walls of the left ventricle. Panel A depicts the 12-hour preservation period. Group I hearts were arrested and stored in UW solution, whereas group II hearts were continuously perfused with blood in the beating, working state. Significant acidosis was encountered in both left ventricular walls of group I when compared with group II $(6.1 \pm 0.03$ vs $7.3 \pm 0.01 \mathrm{pH}$ units, respectively, $P<.001)$. Panel B represents the period of rewarming and instrumentation of the heart in preparation for reperfusion in the working state in group I and cardioplegic arrest in group II using a standard 4:1 blood/cardioplegia ratio. Panel $\mathbf{C}$ depicts the 2-hour reperfusion period. Despite reperfusion, group I remained significantly more acidotic than group II (6.1 \pm 0.03 vs $7.3 \pm 0.01$ $\mathrm{pH}$ units, respectively, $P<.001)$. Data are expressed as mean \pm standard error of the mean.

Group III: Control hearts (control, $n=7$ ). Animals were anesthetized and ventilated as previously described. Median sternotomy was performed and the hearts were excised and immediately placed in standard Krebs-Henseleit solution at $4^{\circ} \mathrm{C}$. This group served as controls for the coronary ring and edema studies.

Reperfusion protocol. For each preserved heart, a second animal was premedicated and instrumented and then exsan- 


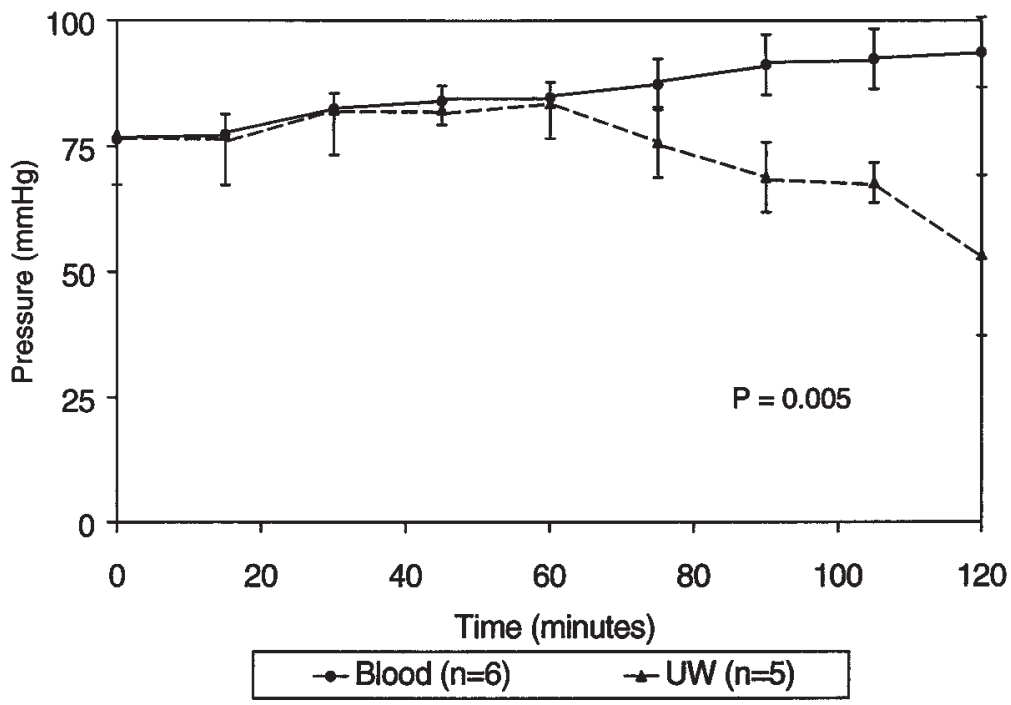

Fig 5. Mean developed pressure for group I (UW) and group II (blood) during the 2 hours of reperfusion. A significant difference was noted between groups I and II over the second hour of reperfusion $(53.3 \pm 16 \mathrm{~mm} \mathrm{Hg}$ vs $90 \pm 6 \mathrm{~mm} \mathrm{Hg}$, respectively, $P=.005)$. Data are expressed as mean \pm standard error of the mean.

Table I. Arterial blood gases, electrolytes, and other blood components

\begin{tabular}{|c|c|c|c|c|}
\hline & \multirow[b]{2}{*}{ Baseline } & \multirow{2}{*}{$\begin{array}{c}\text { Preservation } \\
\begin{array}{c}\text { Group II: Blood } \\
(n=6)\end{array}\end{array}$} & \multicolumn{2}{|c|}{ Reperfusion } \\
\hline & & & $\begin{array}{c}\text { Group I: } U W \\
(n=5)\end{array}$ & $\begin{array}{c}\text { Group II: Blood } \\
\quad(n=6)\end{array}$ \\
\hline WBC count $\left(\times 10^{3} / \mathrm{mm}^{3}\right)$ & $20 \pm 7$ & $4 \pm 2$ & $13 \pm 3$ & $12 \pm 9$ \\
\hline Hemoglobin (g/dL) & $10 \pm 1$ & $8 \pm 25$ & $9 \pm 2$ & $10 \pm 2$ \\
\hline Hematocrit (\%) & $33 \pm 3$ & $26 \pm 4$ & $28 \pm 4$ & $29 \pm 6$ \\
\hline $\mathrm{pH}$ (units) & $7.41 \pm 0.04$ & $7.43 \pm 0.06$ & $7.42 \pm 0.04$ & $7.36 \pm 0.08$ \\
\hline $\mathrm{PCO}_{2}(\mathrm{~mm} \mathrm{Hg})$ & $36 \pm 2$ & $37 \pm 2$ & $39 \pm 2$ & $38 \pm 2$ \\
\hline $\mathrm{Po}_{2}(\mathrm{~mm} \mathrm{Hg})$ & $115 \pm 5$ & $624 \pm 29$ & $677 \pm 41$ & $649 \pm 64$ \\
\hline $\mathrm{O}_{2}$ saturation $(\%)$ & $99 \pm 0.1$ & 100 & 100 & 100 \\
\hline Sodium $(\mathrm{mmol} / \mathrm{L})$ & $142 \pm 2$ & $145 \pm 4$ & $148 \pm 4$ & $146 \pm 4$ \\
\hline Potassium (mmol/L) & $4 \pm 1$ & $5 \pm 1$ & $6 \pm 1$ & $6 \pm 1$ \\
\hline Calcium (mmol/L) & $10.0 \pm 0.3$ & $9.2 \pm 0.1$ & $9.1 \pm 0.4$ & $9.2 \pm 3.0$ \\
\hline Bicarbonate (mmol/L) & $31 \pm 2.7$ & $23 \pm 0.9$ & $25 \pm 2.2$ & $24 \pm 5.5$ \\
\hline BUN (mg/dL) & $10 \pm 3$ & $7 \pm 2$ & $7 \pm 1$ & $11 \pm 2$ \\
\hline Creatinine (mg/dL) & $1.5 \pm 0.1$ & $1.4 \pm 0.3$ & $1.5 \pm 0.2$ & $1.5 \pm 0.1$ \\
\hline Glucose (mg/dL) & $117 \pm 23$ & $99 \pm 24$ & $110 \pm 21$ & $115 \pm 54$ \\
\hline
\end{tabular}

WBC, White blood cell; $\mathrm{PCO}_{2}$, carbon dioxide tension; $\mathrm{Po}_{2}$, oxygen tension; $\mathrm{BUN}$, blood urea nitrogen.

guinated into the perfusion apparatus. Blood in the perfusion circuit was oxygenated with $95 \%$ oxygen $/ 5 \%$ carbon dioxide, $2 \mathrm{~L} / \mathrm{min}$, and warmed to $37^{\circ} \mathrm{C}$ with a hollow-fiber membrane oxygenator (Monolyth, Sorin Biomedical, Irvine, Calif). A leukocyte-depleting filter was not used during reperfusion in either experimental group. On completion of the preservation period, hearts in both groups were instrumented as described in group II and reperfused for 2 hours in the working state. Hearts were allowed to fibrillate for 1 to 2 minutes; if sinus rhythm was not achieved, direct-current shock at increments of 5 joules was used to defibrillate the heart. The afterload column was stabilized at $100 \mathrm{~cm}$ above the coronary ostia.
Pump flow was adjusted to achieve an end-diastolic pressure of $5 \mathrm{~mm} \mathrm{Hg}$.

Measurement of myocardial function. In addition to continuous measurement of intracavitary pressures, Starling curves were generated at 1 and 2 hours of reperfusion by increasing the pump flow to raise the left ventricular enddiastolic pressure by $5 \mathrm{~mm} \mathrm{Hg}$ increments while maintaining standard afterload and measuring cardiac output. Cardiac output was plotted against end-diastolic pressure. The ability of the preserved hearts to return to sinus rhythm, with or without direct-current shock or pacing, was also recorded.

Studies of isolated coronary rings. At the end of the 

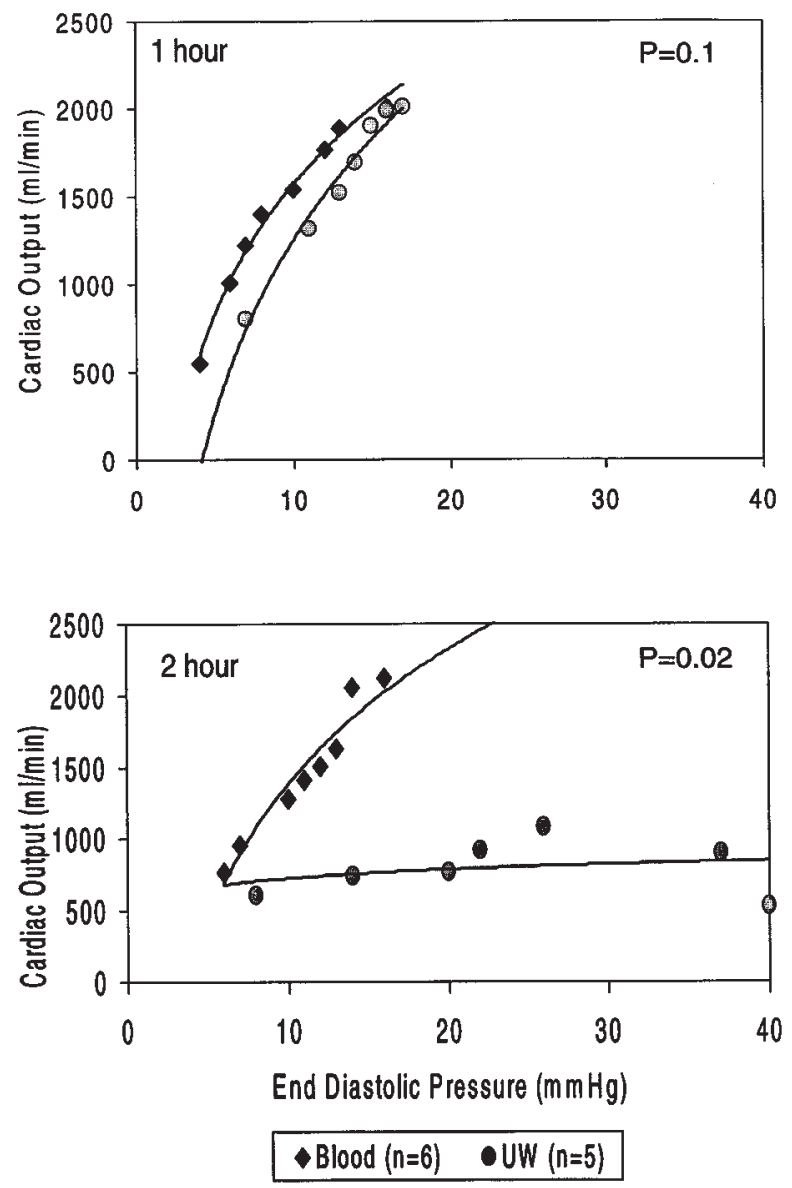

Fig 6. Starling curves generated at 1 hour (top) and 2 hours (bottom) of reperfusion for group I (UW) and group II (blood). The curves were generated by increasing the pump flow to raise the left ventricular end-diastolic pressure by 5 $\mathrm{mm} \mathrm{Hg}$ increments while maintaining standard $100 \mathrm{~cm} \mathrm{H}_{2} \mathrm{O}$ afterload. Cardiac output was plotted against left ventricular end-diastolic pressure. Significance was noted between the slopes of the curves at 2 hours of reperfusion.

experimental protocol in each group, the left anterior descending coronary artery was dissected and placed in $37^{\circ} \mathrm{C}$ standard Krebs-Henseleit solution. The vessels were cleaned of connective tissue, cut into four $3 \times 2 \mathrm{~mm}$ rings, mounted on fine wire tensiometers, and placed in individual organ chambers filled with $10 \mathrm{~mL}$ standard Krebs-Henseleit solution gassed with $95 \%$ oxygen and $5 \%$ carbon dioxide. The rings were allowed to equilibrate at a passive tension of 4 to $6 \mathrm{~g}$ for 60 minutes. The tensiometers were re-zeroed and the rings were then contracted with 50 to $100 \mathrm{nmol}$ of U46619 (a prostaglandin $\mathrm{F}_{2} \alpha$ analog; Sigma Chemical Co, St Louis, Mo) and allowed to stabilize. Once a stable contraction was obtained, coronary vasomotor function was assessed by generating dose-response curves to cumulative concentrations of bradykinin, $10^{-9}$ to $10^{-6} \mathrm{~mol} / \mathrm{L}$ (endothelium-dependent coro- nary vasodilator; Sigma), and of sodium nitroprusside (Nipride; endothelium-independent coronary vasodilator; Sigma), $10^{-7}$ to $10^{-4} \mathrm{~mol} / \mathrm{L}$.

Measurement of myocardial water content. At the end of the reperfusion period and immediately after dissection of the coronary vessels, the hearts from all experimental groups were weighed to obtain their wet weight. Each specimen was then dried in an $80^{\circ} \mathrm{C}$ oven for 48 hours to obtain its dry weight. Myocardial water content (MWC) was calculated as follows ${ }^{9}$ :

MWC $=([$ Wet weight - Dry weight $] /[$ Wet weight $]) \times 100$

Myocardial water content from the 2 experimental groups was compared with that of control hearts in group III.

Assessment of myocardial metabolism. Myocardial tissue $\mathrm{pH}$ was continuously measured by means of a micro-pH electrode/thermistor implanted into the myocardium and connected to the Khuri tissue $\mathrm{pH}$ monitor that measured and stored $\mathrm{pH}$ and temperature data simultaneously. This method has been previously reported. ${ }^{10-12}$ In addition, arterial blood gases were measured hourly during preservation in group II and during reperfusion in both groups.

Measurement of blood components. Blood electrolytes and complete blood count were measured at 4-hour intervals during preservation in group II and hourly during reperfusion in both groups.

Data acquisition and analysis. All function data were continuously recorded and digitally stored with the use of Maclab recording equipment (AD Instruments, Milford, Mass) and also simultaneously displayed on a Power Macintosh computer (Apple Computers, Cupertino, Calif). Statistical analysis was performed with the StatMost statistical package (DataMost Corp, Salt Lake City, Utah). Categorical data were analyzed by the $\chi^{2}$ or 2-tailed Student's $t$ test where appropriate. Continuous data were analyzed by analysis of variance and were expressed in the text as the mean \pm standard deviation and mean \pm standard error for the figures. Data generated by the Starling curves were analyzed by calculating the slope of each curve, and the MannWhitney test was used to compare the slopes of experimental groups I and II. Data on coronary vascular rings were analyzed by calculating the ring relaxation in response to each concentration of the agonists as a percent change of the maximum contraction induced by U46619. One-half maximum effective concentration values $\left(\mathrm{EC}_{50}\right)$ were determined from concentration-response curves of the control rings and were used to compare the experimental groups.

\section{Results}

\section{During preservation}

Contractile function. The integrated mean of the left ventricular developed pressure throughout the 12-hour preservation period in group II was $77.4 \pm 29 \mathrm{~mm} \mathrm{Hg}$ (Fig 3), with a coronary perfusion pressure of $52 \pm 6$ $\mathrm{mm} \mathrm{Hg}$. Normal sinus rhythm was achieved without 


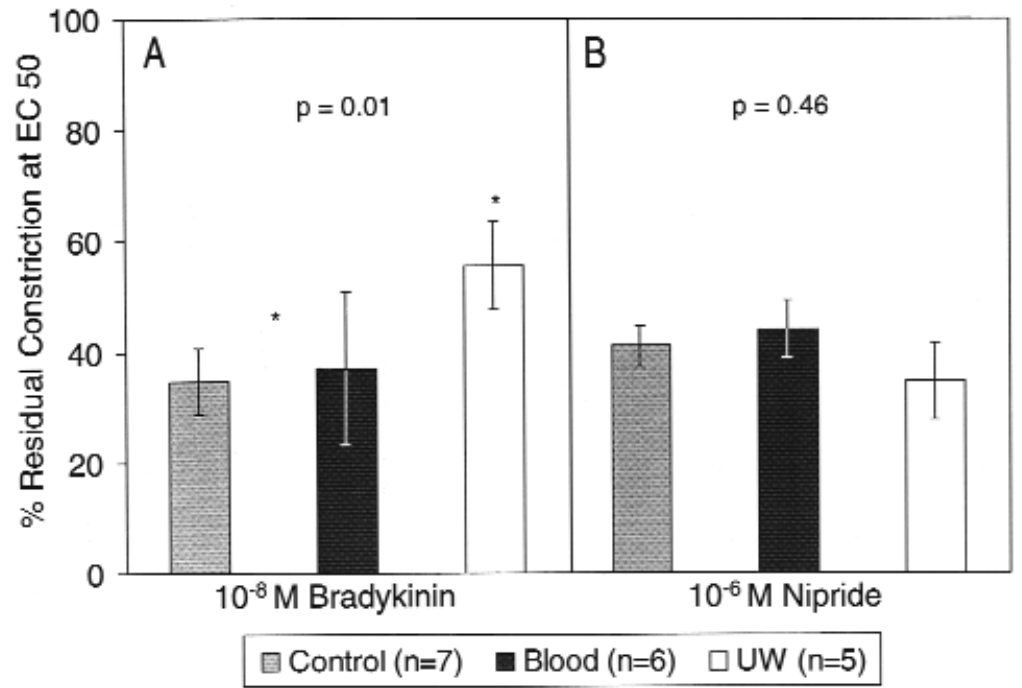

Fig 7. Results from coronary vascular ring studies. Percent residual constriction at $\mathrm{EC}_{50}$ in response to bradykinin and nitroprusside in group I (UW), group II (blood), and group III (control). Significance was noted between groups I and II at a bradykinin concentration of $10^{-8} \mathrm{~mol} / \mathrm{L}$ when compared with controls. No statistical significance was noted between the groups in response to the administration of nitroprusside.

electrical pacing, heart rate during this period averaged $115 \pm 5$ beats/min, and average coronary flow was 506 $\pm 83 \mathrm{~mL} / \mathrm{min}$.

Metabolic function. Marked myocardial tissue acidosis was noticed in group I compared with group II, in which normal physiologic myocardial tissue $\mathrm{pH}$ was observed (Fig 4). Mean myocardial tissue $\mathrm{pH}$ values during the 12-hour preservation period were $6.1 \pm 0.03$ versus $7.3 \pm 0.01 \mathrm{pH}$ units for groups I and II, respectively $(P<.001)$. Blood gas measurements were maintained within normal limits during preservation in group II and during reperfusion in both groups (Table I).

Blood characteristics. Blood components were adequately maintained throughout the 12 -hour preservation period (Table I). The use of a leukocyte-depleting filter significantly reduced the white blood cell count in group II $\left(3.5 \pm 1.9 \times 10^{3} / \mathrm{mm}^{3}\right)$ versus baseline $(20 \pm$ $\left.6 \times 10^{3} / \mathrm{mm}^{3}, P<.0001\right)$.

After reperfusion. On reperfusion, all hearts in group I required direct-current shock to convert to sinus rhythm, whereas all hearts in group II returned to normal sinus rhythm without pacing or direct-current shock.

Contractile function. Throughout the first hour of reperfusion we observed no significant differences in the integrated mean left ventricular developed pressure between groups I $(82.5 \pm 9.4 \mathrm{~mm} \mathrm{Hg})$ and II $(82.3 \pm$ $3.3 \mathrm{~mm} \mathrm{Hg}, P=.8$; Fig 5). However, a marked deterioration of the mean left ventricular developed pressure was observed over the second hour of reperfusion in group I compared with group II $(53.3 \pm 16 \mathrm{~mm} \mathrm{Hg}$ and $90 \pm 6 \mathrm{~mm} \mathrm{Hg}$, respectively, $P=.005$ ). This observation was substantiated by the Starling curves obtained at 1 hour of reperfusion, which were comparable in the 2 groups (Fig 6). However, marked deterioration in left ventricular function was noted in group I as evidenced by the 2-hour Starling curves shown in Fig 6, indicating elevated left ventricular end-diastolic pressure and low cardiac output.

Myocardial water content. A greater degree of edema was observed in group I than in groups II and III (80\% $\pm 1 \%, 73 \% \pm 4 \%, 71 \% \pm 2 \%$ water content, respectively, $P=.01)$. There was no statistically significant difference between group II and group III (73\% $\pm 4 \%$ vs $71 \% \pm 2 \%$ water content, respectively, $P=.14$ ).

Metabolic function. During the preservation period the myocardial $\mathrm{pH}$ fell progressively in group I (Fig 4, $A)$ and reached levels of severe acidosis. This acidosis was not fully corrected during reperfusion (Fig 4, C). Mean myocardial tissue $\mathrm{pH}$ levels over the 2 hours of reperfusion were $6.1 \pm 0.03$ vs $7.3 \pm 0.01 \mathrm{pH}$ units in group I and group II, respectively, $P<.001$. The blood gas results did not differ significantly during reperfusion in the 2 groups (Table I).

Blood characteristics. Blood components were adequately maintained during the 2-hour reperfusion period, and the differences between the groups did not differ significantly (Table I).

Coronary vasomotor function. The $\mathrm{EC}_{50}$ was found 
to be $10^{-8} \mathrm{~mol} / \mathrm{L}$ for bradykinin and $10^{-6} \mathrm{~mol} / \mathrm{L}$ for nitroprusside in the control group (group III). Endothelial dysfunction was noted in group I compared with group II, as evidenced by the response to a $10^{-8}$ mol/L dose of bradykinin $(56 \% \pm 8 \%$ vs $37 \% \pm 14 \%$ residual constriction, respectively, $P=.01$ ) (Fig $7, A$ ). No statistically significant differences were noted in the dose responses to a $10^{-6} \mathrm{~mol} / \mathrm{L}$ dose of nitroprusside $(34.6 \% \pm 6 \%$ vs $45 \% \pm 5 \%$ residual constriction in groups I and II, respectively, $P=.46)($ Fig $7, B)$.

\section{Discussion}

This work demonstrated that maintenance of the donor heart in the beating working state for 12 hours resulted in complete preservation of contractile, metabolic, and vasomotor function as compared with current clinical protocols that use arrest and storage in UW solution over the same period of time. Severe myocardial tissue acidosis was encountered during the preservation period in the UW group that was not completely reversed during reperfusion. Two hours after reperfusion, contractile function in the hearts preserved with UW solution was significantly worse than that in the blood-perfused group. Coronary endothelial function, assessed by the vasodilatory response of preconstricted vascular rings, was markedly compromised in the UW group compared with the blood-perfused group. Myocardial edema was significantly increased in the UW group but was negligible in the blood-perfused group.

This study confirms previous investigations that demonstrated that preservation of the donor heart in the hypothermic arrested state, employing a variety of crystalloid cardioplegic and preservation solutions, does not prevent the onset of time-dependent ischemia-reperfusion injury. Studies in human beings have also demonstrated endothelial dysfunction after donor heart preservation when current hypothermic preservation protocols are used. ${ }^{13,14}$ This lack of protection of the endothelium has been implicated as a possible cause of cardiac allograft vasculopathy. ${ }^{15}$ Several investigators have attempted to improve myocardial protection through the use of hypothermic oxygenated perfusion circuits and a variety of crystalloid cardioplegic solutions. ${ }^{2,3,16}$ These systems have not been applied clinically. Rao, Feindel, and Weise ${ }^{17}$ reported that continuous perfusion of the donor heart with blood cardioplegic solution for 4 hours improved recovery of function as compared with simple storage in UW solution. Despite the improved myocardial function reported in this study, the 4-hour preservation period was not extended. Additionally, coronary endothelial function and myocardial edema were not assessed in these studies.

We used both a blood perfusate and the beating working state, albeit at a reduced workload. Blood perfusate provides better substrate, improves oxygen delivery and oncotic pressure, and contains endogenous free radical scavengers and potent buffers. ${ }^{4-8}$ In our study, the beating state was crucial in ensuring a homogeneous distribution of substrate, which was evidenced by the comparable normal rates of tissue $\mathrm{H}^{+}$washout in both the anterior and posterior walls of the left ventricle.

Chien and associates ${ }^{18,19}$ developed an autoperfusion setup in which a swine heart was continuously perfused with blood preserved in the beating working state for up to 24 hours. Although this work demonstrated the feasibility of safely extending the preservation period of the donor heart, this system was too cumbersome and impractical for widespread clinical use because it required the preservation of the lungs, liver, pancreas, and kidneys en bloc with the heart. As an alternative to the method proposed by Chien and colleagues, we used an extracorporeal circuit to sustain the heart in the beating state despite the potential adverse effects from interactions between blood and the synthetic surface of the extracorporeal circuit ${ }^{20,21}$ and the pump-induced hemolysis. Our pilot studies demonstrated a rise in plasma hemoglobin at 6 hours to $29 \pm 4 \mathrm{mg} / \mathrm{dL}$ from baseline values of $5 \pm 2 \mathrm{mg} / \mathrm{dL}$. To minimize these adverse effects we used a leukocyte-depleting filter during the preservation period in group II. In addition, blood exchange transfusions were used to provide substrate, to ensure an adequate supply of normal red blood cells, to improve oxygen delivery to the heart, and to reduce hemolysis.

Clinical implications. Compared with the current method of hypothermic arrest and storage, our technique demonstrates the ability to safely prolong the preservation period of donor hearts beyond the current 4- to 6-hour limit. The development of a clinical, portable perfusion device for donor organ preservation and transport may increase the pool of available donors by allowing for distant procurement of organs. Prolonged safe preservation not only will allow for better histocompatibility cross-matching, thus reducing the risk of early graft rejection, ${ }^{22}$ but also will create the flexibility to perform the transplant procedure as an elective case. In addition to better recovery of myocardial and coronary vasomotor function after prolonged preservation of the donor heart, this new technique may reduce the incidence of cardiac allograft vasculopathy, the leading cause of late cardiac allograft failure. ${ }^{15}$

An optimal organ preservation technique should 
meet the following conditions: (1) prevention of ischemia-reperfusion injury, (2) minimization of cell swelling and edema, (3) prevention of intracellular acidosis, and (4) provision of substrate for regeneration of high-energy phosphate compounds on reperfusion. $^{23}$ This study demonstrates that preserving the heart in the beating working state, continuously perfused with blood, may prove to be an optimal preservation technique because it fulfills all the aforementioned criteria.

We greatly appreciate the contribution of Mr Kypp W. Morrow and Mr Frank D. McClellan (Medtronic Cardiovascular Inc, Anaheim, Calif), Dr Jerry Ortolano (Pall Filters Biomedical Products Corp, East Hills, NY), and Mr Jep Possee (Sorin Biomedical, Irvine, Calif) in support of this study. We also acknowledge the editorial assistance of Ms Cindy J. M. Bofetiado.

\section{REFERENCES}

1. Burt JM, Copeland JG. Myocardial function after preservation for 24 hours. J Thorac Cardiovasc Surg 1986;92:238-46.

2. Wicomb WN, Cooper DKC, Hassoulas J, Rose AG, Barnard CN. Orthotopic transplantation of the baboon heart after 20 to 24 hours preservation by continuous hypothermic perfusion with an oxygenated hyperosmolar solution. J Thorac Cardiovasc Surg 1982;83:133-40.

3. Wicomb WN, Collins GM. 24-hours rabbit heart storage with UW solution: effects of low-flow perfusion, colloid, and shelf storage. Transplantation 1989;48:6-9.

4. Ferrera R, Larese A, Marcsek P, Guidollet J, Verdys M, Dittmar A, et al. Comparison of different techniques of hypothermic pig heart preservation. Ann Thorac Surg 1994;57:1233-9.

5. Li G, Sullivan J, Hall R. Functional recovery in rabbit heart after preservation with a blood cardioplegic solution and perfusion. J Heart Lung Transplant 1993;12:263-70.

6. Follette D, Mulder D, Maloney J, Buckberg G. Advantage of blood cardioplegia over continuous coronary perfusion or intermittent ischemia. J Thorac Cardiovasc Surg 1978;76:604-17.

7. Julia P, Buckberg G, Acar C, Partington M, Sherman M. Studies of controlled reperfusion after ischemia. XXI. Reperfusate composition: superiority of blood cardioplegia over crystalloid cardioplegia in limiting reperfusion damage-importance of endogenous oxygen free radical scavengers in red blood cells. J Thorac Cardiovasc Surg 1991;101:303-13.

8. Illes R, Silvermen N, Krukenkamp I, Levitsky S. Upgrading acellular to sanguineous cardioplegic efficacy. J Surg Res 1989; 46:543-8

9. Weng ZC, Nicolosi AC, Detwiler PW, Hsu DT, Spotnitz HM. Effect of crystalloid, blood and University of Wisconsin perfusates on weight, water content, and left ventricular compliance in an edema-prone, isolated porcine heart model. J Thorac Cardiovasc Surg 1992;103:504-13.

10. Khuri SF, Healey NA, Zolkewitz M, Khait I, Birjiniuk V, Doursounian M. Determinants of myocardial tissue acidosis during prolonged aortic clamping. Circulation 1996;94(8)(Suppl): I170.

11. Khuri SF, Josa M, Martson W, Braunwald N, Smith B, Tow D, et al. First report of intramyocardial $\mathrm{pH}$ in man. J Thorac Cardiovasc Surg 1984;86:667-78.

12. Axford T, Dearani J, Khait I, Park W, Doursounian M, Neuringer $\mathrm{L}$, et al. Electrode-derived myocardial $\mathrm{pH}$ measurement reflects intracellular myocardial metabolism assessed by phosphorus 31-nuclear magnetic resonance spectroscopy during normothermic ischemia. J Thorac Cardiovasc Surg 1992;103:902-7.

13. Nilsson F, Miller V, Vanhoutte P, McGregor C. Methods of cardiac preservation alter the function of the endothelium in porcine coronary arteries. J Thorac Cardiovasc Surg 1991;102: 923-30.

14. Drinkwater DC, Rudis E, Laks H, Ziv E, Marino J, Stein D, et al. University of Wisconsin solution versus Stanford cardioplegic solution and the development of cardiac allograft vasculopathy. J Heart Lung Transplant 1995;14:891-6.

15. Ventura HO, Mehra MR, Smart FW, Stapleton DD. Cardiac allograft vasculopathy: current concepts. Am Heart J 1995;129:7919.

16. Calhoon JH, Bunegin L, Gelineau JF, Felger MC, Naples JJ, Miller OL, et al. Twelve-hour canine heart preservation with a simple, portable hypothermic organ perfusion device. Ann Thorac Surg 1996;62:91-3.

17. Rao V, Feindel CM, Weisel RD. Donor-blood perfusion improves myocardial recovery following cardiac transplantation. J Heart Lung Transplant 1997;16:667-73.

18. Chien S, Todd E, Diana J, O'Connor N. A simple technique for multiorgan preservation. J Thorac Cardiovasc Surg 1988;95:5561.

19. Chien S, Diana J, Oeltgen P, Salley R. Functional studies of the heart during a 24-hour preservation using a new autoperfusion preparation. J Heart Lung Transplant 1991;10:401-8.

20. Menasché P. The inflammatory response to cardiopulmonary bypass and its impact on postoperative myocardial function. Curr Opin Cardiol 1995;10:597-604.

21. Yoshiki S, Yasuhisa S, Keishi K, Takashi M, Hirotsugu F, Toshihiro $\mathrm{O}$, et al. Attenuation of cardiopulmonary bypassderived inflammatory reactions reduces myocardial reperfusion injury in cardiac operations. J Thorac Cardiovasc Surg 1996; 111:29-35

22. DiSesa VJ, Mull R, Daly ES, Edmunds LH Jr, Mancini DM, Eisen HJ. Cardiac transplant donor heart allocation based on prospective tissue matching. Ann Thorac Surg 1994;58:1050-3.

23. Belzer FO, Southard JH. Principles of solid organ preservation by cold storage. Transplantation 1988;45:673-6.

\section{Discussion}

Dr Vivek Rao (Toronto, Ontario, Canada). I congratulate you on a very nice study. Our group also has been evaluating continuous perfusion with blood, and I have a couple of questions.

What about the confounding factors in terms of the temperature differences between your 2 groups? You kept 1 group at $4{ }^{\circ} \mathrm{C}$ for 12 hours. A lot of evidence has shown that profound hypothermia in itself is going to be injurious to the heart. Second, do you consider this to be a truly portable perfusion circuit?

Dr Hassanein. We designed the experiments to compare our preservation technique to the standard $4^{\circ} \mathrm{C}$ preservation because $4^{\circ} \mathrm{C}$ is the clinically applicable technique. Second, 
we believe that the perfusion circuit is portable. At this time we understand that a significant amount of research and technology has to be introduced into this technique to make it more portable and easier to use.

Dr Ahmad Rajaii-Khorasani (Neptune, $N J$ ). I operated on a patient with a very complex pathologic cardiac condition. The global ischemic time was 6 hours 45 minutes. Myocardial protection was with cold blood cardioplegia, and the patient had a full recovery of cardiac functions soon after release of the crossclamp and was weaned from bypass with minimal inotropic support

What is your opinion on the use of the same system that you described herein, but at hypothermia, with hyperkalemic arrest. Do you think this may produce superior results?

Dr Hassanein. Excellent question. We designed a second experimental protocol addressing hyperkalemic arrest. We have added a third arm to our study in which we tested the hypothesis of continuous perfusion of blood cardioplegic solution at room temperature, $22^{\circ} \mathrm{C}$, not normothermia. We are orthotopically transplanting/reimplanting those hearts after the period of preservation, compared with the 2 techniques that I mentioned in this study. What we noticed is that, even though these hearts respond better than the UW group, significant myocardial edema was noted in this group. That was the limiting factor of this particular method of preservation compared with the others. 